\title{
A Bridging Carbonyl of Unlikely Geometry: On the True Nature of the Technetium Complex $\left[\mathrm{Tc}_{2}(\mu-\mathrm{CO})_{2}(\mathrm{CO})_{6}\left(\mathrm{NC}_{5} \mathrm{H}_{5}\right)_{2}\right]$
}

\author{
Daniel García-Vivó* and Miguel A. Ruiz.* \\ Departamento de Química Orgánica e Inorgánica/IUQOEM, Universidad de Oviedo, \\ E-33071 Oviedo, Spain.
}

\begin{abstract}
The title compound was reported a decade ago by Zuhayra et al. as the main product of the reaction of $\left[\mathrm{Tc}_{2}(\mathrm{CO})_{10}\right]$ with pyridine at room temperature, using the reagent itself as

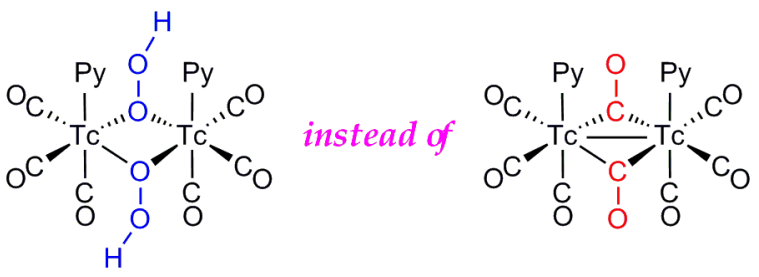
solvent (Inorg. Chem. 2008, 47, 10177-10182). On the basis of an X-ray analysis of the product, a molecular structure was proposed with two bridging carbonyls displaying very unusual geometrical features, not explained at the time. Chemical information, coupled to density functional theory calculations, have now been used to show that the "bridging carbonyls" then proposed from the crystallographic data most likely correspond to bridging hydroperoxide groups, and that the crystals analyzed at the time therefore would correspond to $s y n$ - $\left[\mathrm{Tc}_{2}(\mu-\mathrm{OOH})_{2}(\mathrm{CO})_{6}\left(\mathrm{NC}_{5} \mathrm{H}_{5}\right)_{2}\right]$. This hydroperoxide complex likely was also the bulk product obtained in the above reaction (as a mixture of syn and anti isomers), and not the presumed octocarbonyl complex, computed to bear only terminal carbonyls in any case.
\end{abstract}




\section{Introduction}

We have been working for many years on the synthesis, structure and reactivity of binuclear transition-metal carbonyl complexes, particularly those involving elements of groups 6 to 8, and displaying metal-metal or metal-phosphorus bonds. ${ }^{1-3}$ While looking for binuclear species connected by long intermetallic bonds at the Cambridge Crystallographic Data Centre (CCDC) data base, we came across the structure of a simple, but rare ditechnetium complex having two bridging carbonyls, formulated as $\left[\mathrm{Tc}_{2}(\mu-\mathrm{CO})_{2}(\mathrm{CO})_{6}\left(\mathrm{NC}_{5} \mathrm{H}_{5}\right)_{2}\right](\mathbf{1})$. This complex was reported by Zuhayra et al as the main product of the reaction of $\left[\mathrm{Tc}_{2}(\mathrm{CO})_{10}\right]$ with pyridine at room temperature, using the reagent itself as solvent. ${ }^{4}$ The most unusual features in this molecule (Figure 1) concerned the bridging carbonyls, which apparently featured strongly pyramidalized carbon atoms with very large $\mathrm{C}-\mathrm{O}$ separations of ca. $1.45 \AA$, actually close to the reference value of $1.42 \AA$ for a $\mathrm{C}\left(\mathrm{sp}^{3}\right)-\mathrm{O}$ single bond..$^{5}$ This is quite anomalous, because carbonyl ligands bridging two metal atoms almost invariably display a trigonal planar environment around carbon, and much shorter $\mathrm{C}-\mathrm{O}$ lengths, typically in the range 1.12$1.22 \AA{ }^{6}$ expectedly close to the reference figure of $1.21 \AA$ for a double bond between these atoms. ${ }^{7}$ Other unusual features of the complex were its large intermetallic length of ca. $3.37 \AA$, well above the value of ca. $3.03 \AA$ measured for the parent complex $\left[\mathrm{Tc}_{2}(\mathrm{CO})_{10}\right],{ }^{8}$ and the very presence of bridging carbonyls in the molecule, since no bridging carbonyls are found in simple substitution products of $\left[\mathrm{M}_{2}(\mathrm{CO})_{10}\right]$ dimers of group 7 elements, which instead display structures akin to those of their parent compounds. Surprisingly, none of the above structural oddities were explained in the original paper reporting this compound. We thus wondered whether a serious misinterpretation of the X-ray data had been made at the time, and we have now addressed this matter by using density functional theory (DFT) methods, along with some hypothesis based on the known chemistry of related complexes. As it will be shown below, the most likely structure of an hypothetical disubstituted pyridine derivative of $\left[\mathrm{Tc}_{2}(\mathrm{CO})_{10}\right]$ is $\left[\mathrm{Tc}_{2}(\mathrm{CO})_{8}\left(\mathrm{NC}_{5} \mathrm{H}_{4}\right)_{2}\right]$, with only terminal carbonyls and a staggered conformation, as observed in the parent precursor, while the crystals analysed at the time most likely would correspond to the hydroperoxide-bridged ditechnetium(I) complex $\left[\mathrm{Tc}_{2}(\mu-\mathrm{OOH})_{2}(\mathrm{CO})_{6}\left(\mathrm{NC}_{5} \mathrm{H}_{5}\right)_{2}\right]$. Whether the latter complex was (or not) the major product obtained by Zuhayra et al. cannot be fully ensured at present, since no IR data were reported at the time, although our calculations suggest indirectly that this might have been the case. 

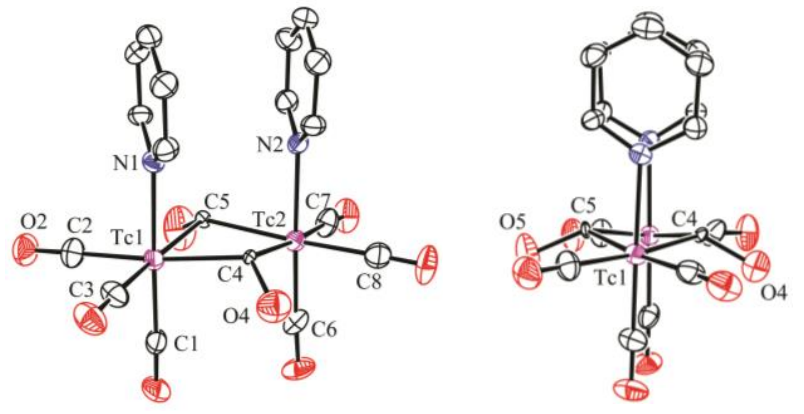

Figure 1. On the left, conventional ORTEP diagram (30\% probability) of compound 1, with $\mathrm{H}$ atoms omitted for clarity. On the right, a view of the molecule along an axis close to the intermetallic line. Both graphics were generated from the cif file included in reference 4 . Selected bond distances $(\AA)$ : Tc1 $\cdots$ Tc2 $=3.370 ; \mathrm{C} 1-\mathrm{O} 1=1.148(13) ; \mathrm{C} 2-\mathrm{O} 2=1.14(2) ; \mathrm{C} 3-\mathrm{O} 3=1.149(15) ; \mathrm{C} 4-\mathrm{O} 4=1.451(14) ; \mathrm{C} 5-\mathrm{O} 5=$ $1.470(14)$

\section{Results and Discussion}

On the Nature of the Molecule in the Crystal. Based on the considerations given above, it was rather clear that the bridging groups present in the molecule of compound $\mathbf{1}$, as determined in the corresponding single-crystal X-ray study, could not be carbonyl ligands (C4-O4 and $\mathrm{C} 5-\mathrm{O} 5$ in Figure 1). Even so, we attempted to find an energy minimum starting from the atomic coordinates determined crystallographically for $\mathbf{1}$, using DFT methods (see the Experimental section for details), ${ }^{9}$ but we failed to find any genuine minimum with bridging carbonyls. Instead, the geometry optimization routine yielded a staggered structure with only terminal carbonyls (syn-1T, Figure 2), as found for the parent complex $\left[\mathrm{Tc}_{2}(\mathrm{CO})_{10}\right],{ }^{8}$ and with a shorter, bonding intermetallic length of $3.072 \AA$, as expected (ca. $3.03 \AA$ in the parent precursor). Of course, there are two possible staggered conformations for 1T, depending on the relative positioning (syn or anti) of the pyridine ligands, and this syn isomer $\left(\mathrm{N}-\mathrm{Tc}-\mathrm{Tc}-\mathrm{N}=44.2^{\circ}\right)$ was computed to be $8.4 \mathrm{~kJ} / \mathrm{mol}$ less stable than anti-1T $\left(\mathrm{Tc}-\mathrm{Tc}=3.091 \AA\right.$ 的 $\left.-\mathrm{Tc}-\mathrm{Tc}-\mathrm{N}=125.2^{\circ}\right)$ in the gas phase (Figure 2). A nearly eclipsed conformation with pyridine ligands in intermediate relative positions $\left(\mathrm{Tc}-\mathrm{Tc}=3.171 \AA\right.$; $\mathrm{N}-\mathrm{Tc}-\mathrm{Tc}-\mathrm{N}=87.6^{\circ}$ ) turned to be a transition state (TS1) connecting both isomers (Figure 2). Its Gibbs free energy was only $33.9 \mathrm{~kJ} / \mathrm{mol}$ higher than the most stable isomer anti-1T, thus enabling fast rotational interconversion between syn and anti isomers at room temperature, a matter to be discussed later on. 


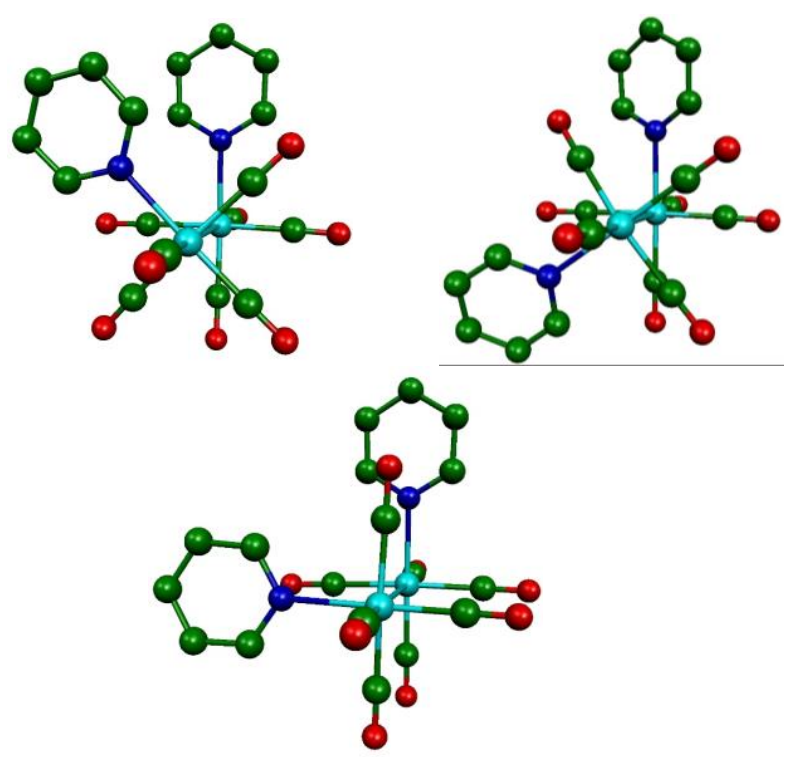

Figure 2. M06L-DFT-optimized structures for syn-1T (left), anti-1T (right), and TS1 (below), with H atoms omitted. Their relative Gibbs free energies at $298 \mathrm{~K}$ in the gas phase were $+8.4,0$, and +33.9 $\mathrm{kJ} / \mathrm{mol}$, respectively.

A closer look at the ORTEP diagram of 1 (Figure 1) reveals that the thermal ellipsoids of atoms C4 and C5 are unusually small, when compared to those of terminal carbonyls. Then, a good hypothesis was that positions C4 and C5 would be actually occupied with atoms having a higher number of electrons. ${ }^{10,11}$ We have considered two possibilities under this idea: (a) the bridging ligands might be OMe groups, and (b) they might be $\mathrm{OOH}$ groups. In both cases, by setting $\mathrm{O}$ atoms at positions $\mathrm{C} 4$ and $\mathrm{C} 5$, the unusual thermal ellipsoids of the model under suspicion would be explained, as well as the large " $\mathrm{C}-\mathrm{O}$ " separation (now turned into conventional single bonds) and pyramidal environment around the bridging atoms. Besides, we note that a methyl group has nine electrons, just one above the eight electrons originally modeled at positions $\mathrm{O} 4$ and $\mathrm{O} 5$, so there would be no much difference at these sites in both models. On the other hand, when modeling hydroperoxide ligands instead of "bridging carbonyls", then O4 and O5 would become genuine $\mathrm{O}$ atoms, although bearing one $\mathrm{H}$ atom each, something to be easily missed in an X-ray diffraction study.

Satisfactorily, we found that, starting from the experimental coordinates of compound 1, now re-formulated alternatively as $s y n$ - $\left[\mathrm{Tc}_{2}(\mu-\mathrm{OMe})_{2}(\mathrm{CO})_{6}\left(\mathrm{NC}_{5} \mathrm{H}_{5}\right)_{2}\right]$ (syn-2), and syn-[ $\left.\mathrm{Tc}_{2}(\mu-\mathrm{OOH})_{2}(\mathrm{CO})_{6}\left(\mathrm{NC}_{5} \mathrm{H}_{5}\right)_{2}\right]$ (syn-3), genuine minimum structures were rapidly found (Figure 3), with geometrical parameters very similar to those determined in the original X-ray analysis (Table 1). 

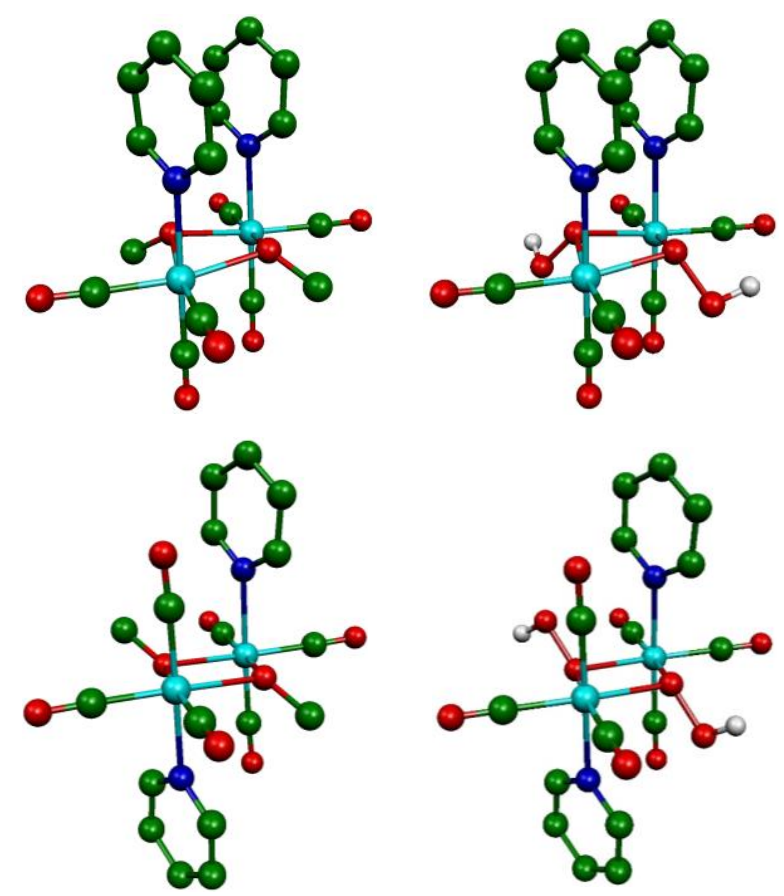

Figure 3. M06L-DFT-optimized structures of compounds syn-2 (left) and syn-3 (right), with most $\mathrm{H}$ atoms omitted. The structures of the corresponding anti isomers are shown below.

Table 1. Selected M06L-DFT-computed bond lengths $(\AA)$ and angles $\left(^{\circ}\right)$ for isomers syn and anti of compounds $\mathbf{2}$ and $\mathbf{3}$, along with their relative Gibbs free energies. ${ }^{a}$

\begin{tabular}{|c|c|c|c|c|c|}
\hline parameter & $1(\exp )^{b}$ & syn-2 & syn-3 & anti-2 & anti-3 \\
\hline $\mathrm{Tc} 1 \cdots \mathrm{Tc} 2$ & 3.370 & 3.402 & 3.412 & 3.456 & 3.458 \\
\hline Tc1-N1 & $2.249(8)$ & 2.287 & 2.287 & 2.298 & 2.291 \\
\hline $\mathrm{Tc} 1-\mathrm{C} 1$ & $1.944(10)$ & 1.916 & 1.927 & 1.912 & 1.915 \\
\hline $\mathrm{Tc} 1-\mathrm{C} 2$ & $1.94(2)$ & 1.918 & 1.915 & 1.912 & 1.918 \\
\hline $\mathrm{Tc} 1-\mathrm{C} 3$ & $1.931(12)$ & 1.912 & 1.910 & 1.914 & 1.912 \\
\hline $\mathrm{Tc} 1-\mathrm{E} 4^{c}$ & $2.170(10)$ & 2.195 & 2.199 & 2.207 & 2.206 \\
\hline $\mathrm{Tc} 1-\mathrm{E}^{c}$ & $2.174(8)$ & 2.190 & 2.197 & 2.173 & 2.184 \\
\hline $\mathrm{O} 4-\mathrm{E} 4^{c}$ & $1.451(14)$ & 1.402 & 1.475 & 1.397 & 1.471 \\
\hline O5-E5 ${ }^{c}$ & $1.470(14)$ & 1.402 & 1.474 & 1.397 & 1.471 \\
\hline$\Sigma(\mathrm{E}-\mathrm{E} 4-\mathrm{E})^{d}$ & 340.1 & 337.6 & 319.3 & 345.4 & 327.2 \\
\hline$\Sigma(\mathrm{E}-\mathrm{E} 5-\mathrm{E})^{d}$ & 341.5 & 337.8 & 319.1 & 345.4 & 327.2 \\
\hline $\mathrm{E} 5-\mathrm{Tc} 1-\mathrm{Tc} 2-\mathrm{E} 4$ & 156.0 & 153.9 & 155.2 & 180.0 & 180.0 \\
\hline$\Delta \mathrm{G}$ (gas phase) & & +4.6 & +23.0 & 0 & 0 \\
\hline$\Delta \mathrm{G}($ acetone soln) & & -5.4 & +0.8 & 0 & 0 \\
\hline
\end{tabular}

${ }^{a}$ Labeling according to Figure 1; $\Delta \mathrm{G}$ values in $\mathrm{kJ} / \mathrm{mol}$, computed at $298 \mathrm{~K}$, relative to the corresponding anti isomers. ${ }^{b}$ Experimental data originally reported for 1, taken from reference $4 .{ }^{c} \mathrm{E} 4$ and E5 denote atoms $(\mathrm{C}$ or $\mathrm{O})$ at the crystallographic sites of $\mathrm{C} 4$ and $\mathrm{C} 5$ atoms, respectively. ${ }^{d}$ Sum of bond angles around the E4 and E5 atoms.

The structures computed for syn-2 and syn-3 both reproduce quite well the geometrical parameters determined in the crystallographic study of $\mathbf{1}$, except for distances involving the metal atoms, which are a bit longer than the experimental values (by less than $0.03 \AA$ ), a common bias in this sort of calculations. ${ }^{9}$ Moreover, both of them reproduce quite precisely the significant puckering of the central $\mathrm{Tc}_{2} \mathrm{E}_{2} \operatorname{ring}(\mathrm{E}=$ $\mathrm{C}$ or $\mathrm{O}$ ) of the molecule present in the crystal (E5-Tc1-Tc2-E4 dihedral angles 
153.9/155.2 vs. $156.0^{\circ}$ ). The pyramidalization at the bridgehead atoms, as measured by the sum of angles around them, is better matched by syn-2, but these angles in the crystal structure (ca. $341^{\circ}$ ) could be influenced by packing forces and therefore might deviate significantly from the values computed in the gas phase. As expected, the $\mathrm{C}-\mathrm{O}$ lengths of $1.402 \AA$ computed for the bridging methoxide groups of syn-2 approach the reference figure of $1.42 \AA$ for a single bond between these atoms. We note that, in all, the computed structure of $\boldsymbol{s y n - 2}$ is similar to those experimentally found for different rhenium complexes with dimetal cores of type $s y n-\left[\operatorname{Re}_{2}(\mu-\mathrm{OR})_{2}(\mathrm{CO})_{6} \mathrm{~L}_{2}\right]$ having bridging alkoxide or hydroxide ligands, and terminal pyridines, dipyridyl and polypyridyl ligands, ${ }^{12}$ a relatively large family of complexes which have been extensively studied because of their photophysical and chemical properties, host-guest interactions, and biological activity.

The average " $\mathrm{C}-\mathrm{O}$ " length determined experimentally for the bridging groups in $\mathbf{1}$ (ca. $1.46 \AA$ ), however, is somewhat higher than the distance computed for syn-2, while the structure computed for the hydroperoxide-bridged complex syn-3 actually gives a better matching value of ca. $1.475 \AA$ for such a distance, now turned into a single O-O bond. We note that hydroxoperoxide- or alkylperoxide-bridged complexes are an absolute rarity in the field of transition-metal carbonyl complexes, ${ }^{13}$ but a few binuclear complexes with these O-donor ligands (mainly involving late- or post-transition metals) have been structurally characterized. ${ }^{14}$ In those cases, the OOR groups behave structurally like bridging alkoxide ligands, and display $\mathrm{O}-\mathrm{O}$ single bond lengths typically in the range 1.45-1.50 $\AA$, in good agreement with the corresponding distance computed for syn-3. Interestingly, many of these complexes have been prepared by the reaction of dioxygen with suitable precursors (usually alkyl complexes).

We have also computed isomers of the above ditechnetium(I) complexes bearing antiparallel pyridine ligands (anti-2 and anti-3), and found them to be more stable than their syn isomers in the gas phase (Figure 3 and Table 1). However, the latter are stabilized in a polar solvent as acetone (the solvent used in the NMR studies of 1), thus enabling the coexistence of syn and anti isomers in solution (see below). Both anti isomers display a nonbonding intermetallic separation (ca. 3.46 $\AA$ ) slightly longer than their syn counterparts, and a flat central $\mathrm{Tc}_{2} \mathrm{O}_{2}$ ring $\left(\mathrm{O} 5-\mathrm{Tc} 1-\mathrm{Tc} 2-\mathrm{O} 4=180.0^{\circ}\right)$. The structure of anti-2 actually is very similar to the one determined crystallographically for the piperidine (pip) dirhenium complex anti-[ $\left.\operatorname{Re}_{2}(\mu-\mathrm{OMe})_{2}(\mathrm{CO})_{6}(\mathrm{pip})_{2}\right]$, which displays an almost identical non-bonding Re $\cdots$ Re separation. ${ }^{15}$

On the Nature of the Bulk Product: Isomers in Solution. In their original paper, Zuhayra et al. reported that compound $\mathbf{1}$ displayed two isomers in solution (denoted at the time as cis-diaxial and trans-diaxial ones), as revealed by ${ }^{1} \mathrm{H}$ NMR measurements, with the cis/trans ratio reaching in a few minutes the equilibrium value of $2: 1$ in 
$\mathrm{Me}_{2} \mathrm{CO}-d_{6}$ solution, when starting from the crystalline material. Since no IR data were reported for this complex, while only NMR resonances of the pyridine ligands were provided, we cannot be sure whether their bulk product corresponded to the presumed formulation of $\left[\mathrm{Tc}_{2}(\mathrm{CO})_{8}(\mathrm{py})_{2}\right](\mathbf{1})$ or, instead, to the actual species present in the crystal investigated by X-ray diffraction, $\left[\mathrm{Tc}_{2}(\mu-\mathrm{OX})_{2}(\mathrm{CO})_{6}\left(\mathrm{NC}_{5} \mathrm{H}_{5}\right)_{2}\right](\mathbf{2}$ or $\mathbf{3})$. From the NMR data reported, however, we can conclude that the second option is more likely. Thus, according to our DFT calculations noted above, the rotational barrier for the conversion between the octocarbonyl isomers syn-1T and anti-1T would be determined by the energy of TS1, which turns out to be quite low, around $34 \mathrm{~kJ} / \mathrm{mol}$ above anti-1T. With such a low rotational barrier, by taking into account the reported chemical shifts for the aromatic resonances of the presumed octocarbonyl isomers in solution, we can predict that the individual pyridine ${ }^{1} \mathrm{H}$ NMR resonances reported for both isomers (should they correspond to syn-1T and anti-1T) actually would be pair-wise averaged at room temperature. ${ }^{16}$ In contrast, a syn/anti rearrangement in the OX-bridged compounds 2 or 3 likely would require the cleavage of a Tc-O bond at intermediate stages, and therefore would have a much higher kinetic barrier, thus enabling the observation of separate NMR resonances for both isomers at room temperature, in agreement with the experimental spectrum reported at the time. In summary, from the reported NMR data we conclude that the bulk crystallized product reported by Zuhayra et al. neither was the presumed octocabonyl complex, but likely the same ditechnetium(I) complex actually present in the crystals investigated. Moreover, since no ${ }^{1} \mathrm{H}$ or ${ }^{13} \mathrm{C}$ NMR resonances attributable to $\mathrm{OMe}$ groups were reported for compound $\mathbf{1}$, we are bound to conclude that the product actually obtained would be the hydroperoxide complex $\mathbf{3}$. In that case, the ${ }^{1} \mathrm{H}$ NMR resonance of the corresponding $\mathrm{OH}$ groups could be very broad and might easily have escaped detection at the time.

How Could It Be Possibly Formed? Having concluded that the bulk crystallized product obtained when reacting $\left[\mathrm{Tc}_{2}(\mathrm{CO})_{10}\right]$ with pyridine at room temperature likely was the ditechnetium(I) species $\mathbf{3}$, rather than the simple substitution product $\mathbf{1}$, the natural question to be answered is where the hydroperoxide ligands could possibly arise from. We are not in a position to reproduce the above reaction in our laboratory. However, if we turn to the known chemistry of $\left[\operatorname{Re}_{2}(\mathrm{CO})_{10}\right]$, we note that the preparation of $\left[\mathrm{Re}_{2}(\mathrm{CO})_{8}\left(\mathrm{NC}_{5} \mathrm{H}_{5}\right)_{2}\right]$ (the $\mathrm{Re}_{2}$ anologue of 1 ) from $\left[\mathrm{Re}_{2}(\mathrm{CO})_{10}\right]$ and pyridine seems to require the use of an amine oxide as a carbonyl scavenger of $\mathrm{CO}$, in order to proceed at room temperature. ${ }^{17}$ On the other hand, many dirhenium polypiridyl complexes with metal cores of type $s y n$ - $\left[\operatorname{Re}_{2}(\mu-\mathrm{OR})_{2}(\mathrm{CO})_{6} \mathrm{~L}_{2}\right]$ have been made by reacting $\left[\mathrm{Re}_{2}(\mathrm{CO})_{10}\right]$ with stoichiometric amounts of the pertinent $\mathrm{N}$-donor ligand in the corresponding alcohol $(\mathrm{ROH})$ or water, although high temperatures are typically required to form these products. ${ }^{12 \mathrm{~b}-\mathrm{i}}$ So it seems than neither the substitution of 
carbonyls in $\left[\operatorname{Re}_{2}(\mathrm{CO})_{10}\right]$ with pyridine nor the oxidative addition of alcohols or water are reactions that can proceed themselves at room temperature. In line with this, a separate experiment carried out by us revealed that stirring $\left[\mathrm{Re}_{2}(\mathrm{CO})_{10}\right]$ in pyridine at room temperature for 4 days caused no detectable transformation on the $\operatorname{Re}_{2}$ substrate. However, upon admission of air into the reaction flask, a slow reaction started to give, after 7 days, a mixture of pyridine complexes exclusively displaying $\operatorname{Re}(\mathrm{CO})_{3}$ fragments and no bridging carbonyls, as revealed by the IR spectrum of the reaction mixture. ${ }^{18}$ Based on the above indirect evidences, and considering that in the preparation of compound 1 Zuhayra et al. did not report the use of inert atmospheres for the whole workup, we tend to think that the presence of dioxygen likely was the critical factor triggering the reaction of $\left[\mathrm{Tc}_{2}(\mathrm{CO})_{10}\right]$ with pyridine at room temperature. As a result, the product thus obtained certainly would not be the octocarbonyl complex 1, but likely the hydroperoxide complex 3 . The latter might be formed if dioxygen would act both as a $\mathrm{CO}$ scavenger (by producing $\mathrm{CO}_{2}$ ) and source of hydroperoxide ligands, in the presence of water. The overall process is computed to be thermodynamically allowed in the gas phase at room temperature (eqs 1 and 2), although obviously it should involve many elementary steps, perhaps worth of further study in the future.

$$
\begin{array}{ll}
{\left[\mathrm{Tc}_{2}(\mathrm{CO})_{10}\right]+2 \mathrm{py}+3 / 2 \mathrm{O}_{2}+\mathrm{H}_{2} \mathrm{O} \rightarrow \text { anti-3 }+4 \mathrm{CO}} & \Delta G_{298}=+94.4 \mathrm{~kJ} / \mathrm{mol} \\
{\left[\mathrm{Tc}_{2}(\mathrm{CO})_{10}\right]+2 \mathrm{py}+5 / 2 \mathrm{O}_{2}+\mathrm{H}_{2} \mathrm{O} \rightarrow \text { anti-3 }+2 \mathrm{CO}+2 \mathrm{CO}_{2}} & \Delta G_{298}=-497.2 \mathrm{~kJ} / \mathrm{mol}
\end{array}
$$

\section{Concluding Remarks}

The reported structure for the hypothetical complex $\left[\mathrm{Tc}_{2}(\mu-\mathrm{CO})_{2}(\mathrm{CO})_{6}\left(\mathrm{NC}_{5} \mathrm{H}_{5}\right)_{2}\right]$ very likely is erroneous. The geometrical parameters of the presumed bridging carbonyls in the crystal are much better interpreted as corresponding to bridging methoxide or hydroperoxide ligands, in agreement with DFT calculations, this also explaining the large intermetallic length of ca. $3.37 \AA$, since no metal-metal bond is then to be proposed for such 36-electron complexes. The most likely structure of the disubstituted pyridine derivative of $\left[\mathrm{Tc}_{2}(\mathrm{CO})_{10}\right]$ is $\left[\mathrm{Tc}_{2}(\mathrm{CO})_{8}\left(\mathrm{NC}_{5} \mathrm{H}_{4}\right)_{2}\right]$, with only terminal carbonyls and a staggered conformation. Two different staggered rotamers differing in the relative positioning of the pyridine ligands (syn and anti) have similar energies, and the computed rotational barrier for their interconversion is very low in the gas phase (ca. $34 \mathrm{~kJ} / \mathrm{mol}$ ). Then we would expect that both isomers might co-exist in solution, but they likely would interconvert rapidly on the NMR timescale, thus giving identical time-averaged pyridine resonances at room temperature, in disagreement with the experimental NMR data reported earlier. The energetic difference between syn and anti isomers of the ditechnetium(I) complexes $\left[\mathrm{Tc}_{2}(\mu-\mathrm{OX})_{2}(\mathrm{CO})_{6}\left(\mathrm{NC}_{5} \mathrm{H}_{5}\right)_{2}\right](\mathrm{X}=\mathrm{Me}$, $\mathrm{OH})$ is neither large, so they might co-exist in solution too, but the corresponding 
interconversion barrier now should be significantly higher, as one Tc-O bond is likely to be cleaved along the process: therefore, they would be expected to display separate NMR pyridine resonances at room temperature, in agreement with the reported NMR data. Thus, the two isomers detected at room temperature by Zuhayra et al. for the bulk product of the reaction of $\left[\mathrm{Tc}_{2}(\mathrm{CO})_{10}\right]$ with pyridine most likely would correspond to the same ditechnetium(I) complex present in the crystal. For the latter, we favor its formulation as the hydroperoxide complex $\left[\mathrm{Tc}_{2}(\mu-\mathrm{OOH})_{2}(\mathrm{CO})_{6}\left(\mathrm{NC}_{5} \mathrm{H}_{5}\right)_{2}\right]$, as no NMR resonances attributable to OMe groups (easily detectable) were reported at the time, although this cannot be fully ensured, as no IR data were provided either for the bulk product or the crystals used in the X-ray study. These missing data would have settled properly the matter, as the presence of $\mathrm{Tc}(\mathrm{CO})_{3}$ and $\mathrm{O}-\mathrm{H}$ groups would have been easily spotted, along with the absence of bridging carbonyls. From this case we should learn an otherwise obvious lesson: Reporting IR data should be a must that both editors and/or reviewers should ask from authors of papers dealing with the structural characterization of new metal carbonyl complexes.

\section{Experimental Section}

Computational Details. All DFT calculations were carried out using the GAUSSIAN09 package, ${ }^{19}$ and the M06L functional. ${ }^{20}$ A pruned numerical integration grid $(99,590)$ was used for all the calculations via the keyword Int=Ultrafine. Effective core potentials and their associated double- $\zeta$ LANL2DZ basis set were used for Tc atoms. ${ }^{21}$ The light elements $(\mathrm{O}, \mathrm{N}, \mathrm{C}$ and $\mathrm{H})$ were described with the $6-31 \mathrm{G}^{*}$ basis. $^{22}$ Geometry optimizations were performed under no symmetry restrictions, using initial coordinates derived from the X-ray data. Frequency analyses were performed for all the stationary points to ensure that a minimum structure with no imaginary frequencies was achieved, except for transition states (one imaginary frequency). Molecular diagrams and vibrational modes were visualized using the MOLEKEL program. ${ }^{23}$ The effect of acetone on the stability of isomers syn and anti of compounds $\mathbf{2}$ and $\mathbf{3}$ in solution was modeled through the polarized-continuum-model (PCM) of Tomasi and co-workers, ${ }^{24}$ using the gas-phase optimized structures.

Supporting Information. A XYZ file including the Cartesian coordinates for all computed species.

Acknowledgment. We thank the MICINN of Spain and FEDER for financial support (Project PGC2018-097366-B-I00), and the SCBI of the Universidad de Málaga, Spain, for access to computing facilities. D.G.-V. would like to thank the SEPE of Spain for unemployment assistance. 


\section{AUTHOR INFORMATION}

Corresponding Authors. E-mail: dgvivo@hotmail.com (D.G.-V.); mara@uniovi.es (M.A.R.).

Author Contribution. The manuscript was written through contributions of all authors.

Notes. The authors declare no competing financial interests.

\section{References}

1. García, M. E.; García-Vivó, D.; Ramos, A.; Ruiz, M. A. Phosphinidene-bridged binuclear complexes. Coord. Chem. Rev. 2017, 330, 1-36.

2. García-Vivó, D.; Ramos, A.; Ruiz, M. A. Cyclopentadienyl and related complexes of the group 6 elements having metal-metal triple bonds: synthesis, structure, bonding and reactivity. Coord. Chem. Rev. 2013, 257, 2143-2191.

3. García, M. E.; Melón, S.; Ruiz, M. A.; Marchiò, L.; Tiripicchio, A. Nitrosyl derivatives of the unsaturated dihydrides $\left[\mathrm{Mn}_{2}(\mu-\mathrm{H})_{2}(\mathrm{CO})_{6}\left(\mu-\mathrm{L}_{2}\right)\right] \quad\left(\mathrm{L}_{2}=\right.$ $\mathrm{Ph}_{2} \mathrm{PCH}_{2} \mathrm{PPh}_{2}$, (EtO) $\left.)_{2} \mathrm{POP}(\mathrm{OEt})_{2}\right)$. J. Organomet. Chem. 2011, 696, 559-567, and references therein.

4. Zuhayra, M.; Lüttzen, U.; Lützen, A.; Papp, L.; Henze, E.; Fiedrichs, G.; Oberdorfer, F. C-H Bond Activation of Coordinated Pyridine: Ortho-Pyridyl Ditechnetiumhydridocarbonyl Metal Cyclus. Crystal Structure and Dynamic Behavior in Solution. Inorg. Chem. 2008, 47, 10177-10182.

5. Cordero, B.; Gómez, V.; Platero-Prats, A. E.; Revés, M.; Echevarría, J.; Cremades, E.; Barragán, F.; Alvarez, S. Covalent Radii Revisited. Dalton Trans. 2008, 28322838.

6. Range of distances according to a search at the Cambridge Crystallographic Data Centre database (updated August 2019). The search yielded some 5000 complexes, with only about 55 of them displaying C-O distances above $1.30 \AA$, only about 15 of them with $\mathrm{C}-\mathrm{O}$ distances above $1.40 \AA$. In most of the latter cases, the precision in the $\mathrm{C}-\mathrm{O}$ distance was quite low, due to different causes, and the reported figures likely are not fully significant.

7. Pyykkö, P.; Atsumi, M. Molecular Double-Bond Covalent Radii for Elements LiE112. Chem. Eur. J. 2009, 15, 12770-12779.

8. (a) Bailey, M. F.; Dahl, L. F. The Crystal Structure of Ditechnetium Decacarbonyl. Inorg. Chem. 1965, 4, 1140-1145. (b) Sidorenko, G. V.; Miroslavov, A. E.; Grigor'ev, M. S.; Gurzhiy, V. V.; Lumpov, A. A.; Mikhael, V. A., Suglobov, D. N. Hydrolysis of $\mathrm{Tc}(\mathrm{CO})_{6}{ }^{+}$cation in aqueous solutions. Crystal and molecular 
structures of the identified products: $\mathrm{Tc}_{2}(\mathrm{CO})_{10}$ and $\mathrm{Tc}_{3} \mathrm{H}_{3}(\mathrm{CO})_{12}$. Radiochem. 2011, 53, 44-50.

9. (a) Cramer, C. J. Essentials of Computational Chemistry, 2nd Ed.; Wiley: Chichester, UK, 2004. (b) Koch, W.; Holthausen, M. C. A Chemist's Guide to Density Functional Theory, 2nd Ed.; Wiley-VCH: Weinheim, 2002.

10. Misidentifying an atom as another one having fewer electrons is expected to render abnormally low thermal parameters when refining a molecular structure by singlecrystal X-ray diffraction methods. See Stout, G. H.; Jensen, L. H. X-Ray Structure Determination, $2^{\text {nd }}$ Ed.; John Wiley \& Sons: New York, 1989. Chapter 16, p. 358.

11. For some examples of atom misidentification in crystal structures, see, for instance: (a) Harlow, R. L. Troublesome Crystal Structures: Prevention, Detection and Resolution. J. Res. Natl. Inst. Stand. Technol. 1996, 101, 327-339. (b) Parkin, G. Bond-Stretch Isomerism in Transition Metal Complexes: A Reevaluation of Crystallographic Data. Chem. Rev. 1993, 93, 887-911.

12. For some representative examples, see: (a) Woessner, S. M.; Helms, J. B.; Shen, Y.; Sullivan, B. P. Self-Assembly of Ligand-Bridged Molecular Rectangles Containing fac- $\mathrm{Re}(\mathrm{CO})_{3}$ Corners. Inorg. Chem. 1998, 37, 5405-5407. (b) Manimaran, B.; Rajendran, T.; Lu, Y.-L.; Lee, G.-H.; Peng, S.-M.; Lu, K.-L. Novel one-pot synthesis of luminiscent neutral rhenium-based molecular rectangles. $J$. Chem. Soc., Dalton Trans. 2001, 515-517. (c) Manimaran, B.; Rajendran, T.; Lu, Y.-L.; Lee, G.-H.; Peng, S.-M.; Lu, K.-L. Self-Assembly of Fourteen Components into a Soluble, Neutral, Metalloprismatic Cage. Eur. J. Inorg. Chem. 2001, 633636. (d) Manimaran, B.; Thanasekaran, P.; Rajendran, T.; Liao, R.-T.; Liu, Y.-H.; Lee, G.-H.; Peng, S.-M.; Rajagopal, S.; Lu, K.-L. Self-Assembly of OctarheniumBased Neutral Luminiscent Rectangular Prisms. Inorg. Chem. 2003, 42, 4795-4797. (e) Orsa, D. K.; Haynes, G. K.; Pramanik, S. K.; Iwunce, M. O.; Greco, G. E.; Krause, J. A.; Ho, D. M.; Williams, A. L.; Hill, D. A.; Mandal, S. K. Synthesis, characterization, and fluorescence and cytotoxicity studies of a tetrarhenium molecular rectangle. Inorg. Chem. Commun. 2007, 10, 821-824. (f) Thanasekaran, P.; Wu, J.-Y.; Manimaran, B.; Rajendran, T.; Chang, I-J.; Rajagopal, S.; Lee, G.H.; Peng, S.-M.; Lu, K.-L. Agregate of Alkoxy-Bridged Re(I)-Rectangles as a Probe for Photoluminiscence Quenching. J. Phys. Chem. A 2007, 111, 1095310960. (g) Rajakannu, P.; Hussain, F.; Shankar, B.; Sathiyendiran, M. Unprecedented single-crystal-to-single-crystal topochemical conformational change and photoreduction of ethylene units in $\pi$-stacked metallomacrocycle. Inorg. Chem. Commun. 2012, 26, 46-50. (h) Sathish, V.; Babu, E.; Ramdass, A.; Lu, Z.-Z.; Chang, T.-T.; Velayudham, M.; Thanasekaran, P.; Lu, K.-L.; Li, W.-S.; Rajagopal, S. Photoswitchable Alkoxy-Bridged Binuclear Rhenium(I) Complexes- A Potential 
Probe for Biomolecules and Optical Cell Imaging. RSC Adv. 2013, 3, 18557-18566.

(i) Shankar, B.; Elumalai, P.; Hussain, F.; Sathiyendiran, M. Synthesis and characterization of tetragonal prismatic $\pi$-stacked metallacycles. J. Organomet. Chem. 2013, 732, 130-136.

13. Rauchfuss and Schilter have reported the formation of $[\mathrm{FeNi}(\mu-\mathrm{OOH})(\mu$ $\left.\left.\mathrm{S}_{2} \mathrm{C}_{3} \mathrm{H}_{6}\right)(\mathrm{CO})_{3}(\mathrm{dppe})\left(\mathrm{PPh}_{3}\right)\right] \mathrm{BF}_{4}$ upon reaction of the corresponding hydridebridged precursor with $\mathrm{H}_{2} \mathrm{O}_{2}$, but no X-ray analysis was performed on this product. See Schilter, D.; Rauchfuss, T. B. Nickel-iron dithiolates related to the deactivated [NiFe]-hydrogenases. Dalton Trans. 2012, 41, 13324-13329. No other OOH- or OOR-bridged carbonyl complexes appear to have been reported so far.

14. A search at the Cambridge Crystallographic Data Centre database (updated August 2019) yielded some 25 complexes having $\mathrm{M}-\mathrm{O}(\mathrm{OX})-\mathrm{M}$ connections ( $\mathrm{X}=\mathrm{H}$ or $\mathrm{C}$ ). For some recent representative examples see, for instance: (a) Kulkarni, N. V.; Das, A.; Ridlen, S. G.; Maxfield, E.; Adiraju, V. A. K.; Yousufuddin, M.; Dias, H. V. R. Fluorinated triazapentadienyl ligand supported ethyl zinc(II) complexes: reaction with dioxygen and catalytic applications in the Tishchenko reaction. Dalton Trans. 2016, 45, 4896-4906. (b) Kindermann, N.; Dechert, S.; Demeshko, S.; Meyer, F. Proton-Induced, Reversible Interconversion of a $\mu$-1,2-Peroxo and a $\mu-1,1$ Hydroperoxo Dicopper(II) Complex. J. Am. Chem. Soc. 2015, 137, 8002-8005. (c) Kubisiak, M.; Zelga, K.; Justyniak, I.; Tratkiewicz, E.; Pietrzak, T.; Keeri, A. R.; Ochal, Z.; Hartenstein, L.; Roesky, P. W.; Lewinski, J. Catalytic Epoxidation of Enones Mediated by Zinc Alkylperoxide/tert-BuOOH Systems. Organometallics 2013, 32, 5263-5265. (d) Lewinski, J.; Sliwinski, W.; Dranka, M.; Justyniak, I.; Lipkowski, J. Reactions of $\left[\mathrm{ZnR}_{2}(\mathrm{~L})\right]$ Complexes with Dioxygen: A New Look at an Old Problem. Angew. Chem. Int. Ed. 2006, 45, 4826-4829.

15. Franklin, B. R.; Herrick, R. S.; Ziegler, C. J.; Cetin, A.; Barone, N.; Condon, L. R. Reactions of the $\operatorname{Re}(\mathrm{CO})_{3}\left(\mathrm{H}_{2} \mathrm{O}\right)_{3}{ }^{+}$Synthon with Monodentate Ligands under Aqueous Conditions. Inorg. Chem. 2008, 47, 5902-5909.

16. The relationship between the coalescence temperature $\left(T_{c}\right)$ of two resonances (differing by $\Delta v \mathrm{~Hz}$ ) related by an exchange processes with the corresponding activation energy at that temperature $\left(\Delta \mathrm{G}_{\mathrm{Tc}}{ }^{\#}\right)$ can be estimated through the modified Eyring equation $\Delta \mathrm{G}_{\mathrm{Tc}^{\#}}=19.14 \mathrm{~T}_{\mathrm{c}}\left[9.97+\log \left(\mathrm{T}_{\mathrm{c}} / \Delta v\right)\right]$ (in $\left.\mathrm{J} / \mathrm{mol}\right)$. See: Günter, H. NMR Spectroscopy; Wiley: Chichester, UK, 1980, p 243. The largest frequency separation between corresponding resonances related by the dynamic process in the $500 \mathrm{MHz}{ }^{1} \mathrm{H}$ NMR spectrum recorded by Zuhayra et al. at $301 \mathrm{~K}$ corresponds to the ortho hydrogens of this product $(\Delta v=122 \mathrm{~Hz})$. For these resonances to be distinguished from each other at $301 \mathrm{~K}$, the coalescence temperature should be substantially higher than $301 \mathrm{~K}$ or, put in another way, the kinetic barrier for the 
corresponding process should be significantly higher than $60 \mathrm{~kJ} / \mathrm{mol}$, according to the above equation, far above the value of just $34 \mathrm{~kJ} / \mathrm{mol}$ computed for the syn1T/anti-1T exchange in the gas phase.

17. Koelle, U. Aminoxidinduzierte ligandensubstitution anübergangsmetallcarbonylen. II. J. Organomet. Chem. 1978, 155, 53-62.

18. At this stage the pyridine solution only displayed C-O stretches at 2035 (m), 2017 (vs), 2004 (m, sh), 1914 (vs, br) and 1872 (vs, br) $\mathrm{cm}^{-1}$. These values are comparable, for instance, to those of $\left[\operatorname{Re}_{2}(\mu-\mathrm{OH})_{2}(\mathrm{CO})_{6}\left(4,4^{\prime}-\mathrm{bpy}\right)\right]_{2}(2018,2004$, $1904,1881 \mathrm{~cm}^{-1}$ in $\mathrm{MeCN}$ solution) and related alkoxide-bridged complexes, see reference $10 \mathrm{a}$.

19. Frisch, M. J.; Trucks, G. W.; Schlegel, H. B.; Scuseria, G. E.; Robb, M. A.; Cheeseman, J. R.; Scalmani, G.; Barone, V.; Mennucci, B.; Petersson, G. A.; Nakatsuji, H.; Caricato, M.; Li, X.; Hratchian, H. P.; Izmaylov, A. F.; Bloino, J.; Zheng, G.; Sonnenberg, J. L.; Hada, M.; Ehara, M.; Toyota, K.; Fukuda, R.; Hasegawa, J.; Ishida, M.; Nakajima, T.; Honda, Y.; Kitao, O.; Nakai, H.; Vreven, T.; Montgomery, J. A., Jr.; Peralta, J. E.; Ogliaro, F.; Bearpark, M.; Heyd, J. J.; Brothers, E.; Kudin, K. N.; Staroverov, V. N.; Kobayashi, R.; Normand, J.; Raghavachari, K.; Rendell, A.; Burant, J. C.; Iyengar, S. S.; Tomasi, J.; Cossi, M.; Rega, N.; Millam, J. M.; Klene, M.; Knox, J. E.; Cross, J. B.; Bakken, V.; Adamo, C.; Jaramillo, J.; Gomperts, R.; Stratmann, R. E.; Yazyev, O.; Austin, A. J.; Cammi, R.; Pomelli, C.; Ochterski, J. W.; Martin, R. L.; Morokuma, K.; Zakrzewski, V. G.; Voth, G. A.; Salvador, P.; Dannenberg, J. J.; Dapprich, S.; Daniels, A. D.; Farkas, Ö.; Foresman, J. B.; Ortiz, J. V.; Cioslowski, J.; Fox, D. J. ; Gaussian 09, Revision A.02; Gaussian, Inc.: Wallingford, CT, USA, 2009.

20. Zhao Y.; Truhlar, D. G. A new local density functional for main-group thermochemistry, transition metal bonding, thermochemical kinetics, and noncovalent interactions. J. Chem. Phys. 2006, 125, 194101: 1-18.

21. Hay, P. J.; Wadt, W. R. Ab initio effective core potentials for molecular calculations. Potentials for potassium to gold including the outermost core orbitals. J. Chem. Phys. 1985, 82, 299-310.

22. (a) Hariharan, P. C.; Pople, J. A. Influence of polarization functions on MO hydrogenation energies. Theor. Chim. Acta 1973, 28, 213-222. (b) Petersson, G. A.; Al-Laham, M. A. A complete basis set model chemistry. II. Open-shell systems and the total energies of the first-row atoms. J. Chem. Phys. 1991, 94, 6081-6090. (c) Petersson, G. A.; Bennett, A.; Tensfeldt, T. G.; Al-Laham, M. A.; Shirley, W. A.; Mantzaris, J. A complete basis set model chemistry. I. The total energies of closedshell atoms and hydrides of the first-row elements. J. Chem. Phys. 1988, 89, 21932218 . 
23. Portmann, S.; Luthi, H. P. MOLEKEL: An Interactive Molecular Graphics Tool. CHIMIA 2000, 54, 766-770.

24. (a) Tomasi, J.; Mennucci, B.; Cammi, R. Quantum mechanical continuum solvation models. Chem. Rev. 2005, 105, 2999-3093. (b) Cossi, M.; Barone, V.; Cammi, R.; Tomasi, J. Ab initio study of solvated molecules: a new implementation of the polarizable continuum model. Chem. Phys. Lett. 1996, 255, 327-335, and references therein. 